Published in final edited form as:

Curr Opin Cell Biol. 2017 December ; 49: 91-98. doi:10.1016/j.ceb.2017.12.010.

\title{
Mitochondrial regulation of hematopoietic stem cells
}

\author{
Hans-Willem Snoeck ${ }^{1,2,3}$ \\ ${ }^{1}$ Columbia Center for Human Development, Columbia University Medical Center, New York, NY \\ 10032, USA \\ ${ }^{2}$ Department of Microbiology and Immunology, Columbia University Medical Center, New York, \\ NY 10032 \\ ${ }^{3}$ Department of Medicine, Columbia University Medical Center, New York, NY 10032, USA
}

\begin{abstract}
Hematopoietic stem cells (HSCs) preferentially use glycolysis rather than mitochondrial oxidative phosphorylation for energy production. While glycolysis in HSC is typically viewed as response to a hypoxic bone marrow environment that protects HSC from damaging reactive oxygen species, other interpretations are possible. Furthermore, recent evidence directly supports a critical role for mitochondria in the maintenance and function of HSCs that goes beyond ATP production. Here, we review recent advances in our understanding of metabolism and the role of mitochondria in the biology of HSCs.
\end{abstract}

\section{Introduction}

Hematopoietic stem cells (HSCs) reside in the bone marrow (BM), are quiescent, can self renew, and generate all lineages of the hematopoietic system. Despite the identification of multiple cytokines and of more than 200 genes that affect HSC function in knockout studies[1], a coherent understanding of steady-state function and homeostatic responses of HSCs has not emerged yet, while reliable maintenance of HSCs in vitro has not been achieved. The metabolism of HSCs has therefore garnered increasing interest. Mitochondria produce ATP from fatty acid, glutamine and glucose oxidation. However, they are also involved in calcium homeostasis[2], cell death[3], innate immunity[4], the generation of reactive oxygen species (ROS)[5], and the synthesis of biosynthetic intermediates and substrates for epigenetic modifications[6]. Mitochondria may therefore play a role in incompletely understood functional attributes of HSCs, such as reduced susceptibility to stress compared to progenitor cells[ $[7,8]$, and the capacity to make multiple cell fate decisions.

Corresponding author: Hans-Willem Snoeck, MD, PhD, hs2680@ columbia.edu.

Publisher's Disclaimer: This is a PDF file of an unedited manuscript that has been accepted for publication. As a service to our customers we are providing this early version of the manuscript. The manuscript will undergo copyediting, typesetting, and review of the resulting proof before it is published in its final citable form. Please note that during the production process errors may be discovered which could affect the content, and all legal disclaimers that apply to the journal pertain. 


\section{HSC metabolism}

To produce ATP HSCs preferentially use the less efficient process of glycolysis, while mitochondrial oxidative phosphorylation (OxPhos) is more active in progenitors (Fig. 1)[911]. Glycolytic ATP production in stem cells is not a general rule, however, as muscle satellite cells are oxidative and transit to glycolytic metabolism upon differentiation[12]. Furthermore, fetal liver HSCs may be more oxidative than their adult counterparts[13]. While in cancer cells aerobic glycolysis allows rapidly proliferating cells to build biomass[14], glycolysis in quiescent HSCs is typically viewed as a response to a hypoxic $\mathrm{BM}$ environment, seen to benefit HSC maintenance by limiting the production of mitochondrial (m) ROS, the levels of which are low in HSCs and to which HSCs are exquisitely sensitive[15]. This concept deserves more refined analysis however.

\section{The hypoxic bone marrow niche}

Several lines of evidence suggest that a hypoxic environment is important for HSC maintenance. Progenitor and stem cells are better maintained in hypoxic than in normoxic conditions in vitro [16,17]. Furthermore, HSCs show enhanced staining in situ and after isolation for the hypoxia marker, pimonidazole[18-22], suggesting residence in a hypoxic niche. Using oxygen-sensitive probes and two-photon live imaging, it was shown that BM is indeed hypoxic particularly near vascular niches, where most HSCs reside[23], but that hypoxia correlated with cellularity and therefore possibly with oxygen consumption[24]. Nombela-Arrieta et al. found that irrespective of their location, the HSCs stained more intensely for pimonidazole[25]. As these authors[25] and others[21] point out however, pimonidazole forms adducts with cellular constituents after reacting with electrons emanating from the respiratory chain that do not find an oxygen acceptor. Pimonidazole staining therefore detects low OxPhos, and not necessarily hypoxic cells.

\section{Glycolysis in HSCs}

Anaerobic glycolysis is driven by dimers of hypoxia-induced factor (HIF) $1 a$ or HIF2 $a$ and HIF $1 \beta$ that are destabilized by prolyl hydroxylation of HIF1a or HIF2 $a$ by oxygen-sensitive dioxygenases (PHD enzymes), which targets those for degradation[26]. HSCs in mice with inducible deletion of HIF1a or with deletion of Pdk2 and Pdk4, which inhibit entry of pyruvate into the TCA thus enhancing glycolysis at the expense of respiration, were reported to lose quiescence and display defects after transplantation[11,19]. Despite these findings, the role of HIF in HSCs is controversial, as it was subsequently reported that HIF1a and HIF2 $\alpha$ individually are dispensable for HSC function[27,28], while deletion of HIF1 $\beta$ or of both HIF1 $a$ and HIF2 $a$ only resulted in a subtle loss of HSC function and minimal changes in the expression of glycolytic enzymes[29]. Furthermore, although, similar to $\mathrm{Pdk} 2^{-/} \mathrm{Pdk} 4^{-/}$mice, HSC function is impaired in Pdk ${ }^{-/-}$mice, these authors observed that conditional deletion of HIFla had no effect on the expression any Pdk isoforms in vivo [30]. Mice mutant for either of two genes involved in enhanced glycolysis in tumor cells, Pkm2 and Ldha, also displayed predominantly reduced progenitor proliferation, while a HSC defect could be only elicited after serial transplantation of Ldha ${ }^{-/}$HSCs[21]. Finally, HIF1a may not only be directly stabilized by hypoxia (except in very severe hypoxia), but 
also, and perhaps primarily, by mROS arising through as yet unclear mechanisms during hypoxia[5,31-33]. This conflicts with the notion that mROS, which are detrimental to HSC maintenance, are low in HSCs[34] (Fig. 2). Taken together, it is possible that glycolysis, while important for HSC maintenance, is not primarily driven by a HIF-mediated response to hypoxia. Instead, enhanced glycolysis may be hardwired, or be a compensatory response to hardwired attenuation of mitochondrial respiration (Fig. 1).

\section{Mitochondria mass and turnover in HSCs}

In keeping with their glycolytic nature, HSCs have been reported to possess low mitochondrial mass $[9,11,35-38]$ sustained by active elimination through mitophagy, which has been suggested to be critical for HSC maintenance[36,39,40•]. However, elevated mitophagy should be balanced by mitochondrial biogenesis to avoid depletion, a condition only known to occur in erythroid precursors[41]. Recent evidence shows that mitochondrial mass in HSCs is stable throughout life span, however, while mitochondrial turnover capacity is in fact lower in HSCs than in progenitors[42•]. The role of mitophagy therefore remains a matter of debate. The same is true for mitochondrial mass, which is typically measured by staining with fluorescent mitochondrial dyes[9,11,35-38,43]. However, HSCs are endowed with xenobiotic efflux pumps[44,45]. Mitotracker green, a commonly used fluorescent dye to measure mitochondrial content, undergoes efflux from HSCs, leading to artifactually low fluorescence. mtDNA quantification, enumeration of mitochondrial nucleoids and fluorescence intensity of a genetically encoded mitochondrial reporter indicated that HSCs have higher mitochondrial mass than lineage-committed progenitors and mature cells[42•]. HSCs may therefore have a high set-point for mitochondrial mass and low mitochondrial turnover.

\section{Enhanced respiration is detrimental for HSC maintenance and function}

Despite their high mitochondrial mass, baseline respiration and maximal respiration in purified HSCs was much lower than in progenitors, even in normoxic conditions[11,40•, 42•]. Evidence indicates that low respiration is required for HSC maintenance (Fig. 3). For example, deletion of the negative regulator of mTOR, TSC1, compromised HSC function associated with enhanced mitochondrial biogenesis and ROS production[46]. Knockout of Sirt7, which increases mitochondrial unfolded protein stress, mitochondrial biogenesis and respiration in cell lines, impaired HSC function with loss of quiescence[37••]. Mice conditionally deleted for mitochondrial carrier homologue 2 (Mcth2) show compromised HSC function with enhanced cycling and increased respiration[47]. The detrimental effects on HSC function of Pdk deletion[11,30] may also be explained by enhanced TCA flux rather than by reduced glycolysis. Finally, HSC with defective autophagy show enhanced oxidative metabolism[40•]. Consistent with these findings, HSCs may be less susceptible to reduced mitochondrial function than progenitors. Polg ${ }^{\text {mut }}$ mice, which accumulate mtDNA mutations, showed impaired lymphoid and erythroid differentiation, but did not have HSC defects[48]. Furthermore, Ptpmt1, a mitochondrial phosphatase targeting phosphatidylinositol phosphates that increase respiration, is required for early HSC differentiation, but inhibits HSC expansion in vivo [49]. Together, these findings may be consistent with reduced OxPhos detected by pimonidazole staining $[16,18,22,24]$ and with 
the remarkably low ATP levels in $\mathrm{HSCs}[9,50]$. While it is possible that reduced respiration may be required to limit mROS production, whether, and if so, why low OxPhos is directly required for HSC maintenance is not known, but is worthy of more incisive investigation.

\section{Requirement for intact mitochondrial function in HSCs: role in epigenetics?}

Although enhanced respiration compromises HSC function, several knockout mouse models with impaired HSC function also showed mitochondrial dysfunction, although to what extent this explained the observed HSC defects is unclear[51-55]. Recent reports however directly linked mitochondrial dysfunction to HSC impairment (Fig. 3). The underlying mechanism may be epigenetic, as mitochondria are involved in the synthesis of epigenetic marks and of inhibitors of epigenetic modifications (Fig. 4)[6]. One-carbon metabolism, which provides methyl groups for DNA and histone methylation, takes place in part in mitochondria[56]. Demethylases, including the JmjC-containing histone lysine demethylases (KDMs) and TETs, which promote DNA demethylation, are dioxygenases that convert oxygen and 2-oxoglutarate (2OG) into succinate and $\mathrm{CO}_{2}$ during hydroxylation of their respective substrates. This reaction is inhibited by succinate and fumarate, and by a byproduct of 2OG metabolism, L(S)-2-hydroxyglurate (L(S)2HG)[6]. Acetyl-CoA generated in mitochondria can be recycled via citrate to the nucleus for acetylation of histones and other proteins[57]. Mitochondrial function also determines the NAD ${ }^{+} / \mathrm{NADH}$ ratio, which is sensed by a class of NAD-dependent deacetylases, the sirtuins. A direct role for mitochondria in epigenetic regulation was suggested in cell lines where an intact TCA, even with a deficient respiratory chain, is sufficient to maintain histone $\mathrm{H} 3$ acetylation[58•]. In autophagy-deficient HSCs, increased respiration was associated with changes in methylation status at select loci[40•], although this study did not prove a causal link between mitochondrial function and differentially methylated regions. Several other studies provided evidence for a link between reduced mitochondrial function and epigenetic changes. Conditional deletion of Riske iron-sulphur protein (Risp), a component of complex III of the electron transport chain, in the hematopoietic system was embryonic lethal and associated with impaired erythroid maturation, enhanced HSC cycling and a profound repopulation defect. Inducible deletion in adults also resulted in severe HSC defects[59••]. Histone hypermethylation and hypoacetylation as well as DNA hypermethylation were observed in enriched stem and progenitor cells. These changes were associated with reduced NAD/ NADH ratio, and increased 2-OG, fumarate, succinate and L(S)-2HG levels, all of which are theoretically conducive to genome-wide epigenetic changes[59・•] (Fig. 3,4). Deletion of the mitochondrial DNA replication and transcription factor, Tfam, on the other hand, caused profound defects in erythroid development associated with histone hyperacetylation, possibly due to accumulation of the HDAC inhibitor, $\beta$-hydroxybutyrate[60•]. Fumarate hydratase $(\mathrm{FH})$ is a tumor suppressor enzyme of the TCA that is also present in the cytoplasm where it participates in arginine and purine synthesis. Conditional deletion in the hematopoietic system was embryonic lethal and profoundly impaired fetal erythropoiesis and HSC function[61••]. In contrast to Vav-iCre.Risp ${ }^{\mathrm{fl} / \mathrm{fl}}$ mice, however, Vav-iCre. $\mathrm{Fh}^{\mathrm{fl} / \mathrm{fl}}$ mice displayed increased HSC numbers in the fetal liver. Restoration of cytoplasmic FH rescued lethality, while HSCs showed a defect in the lymphoid lineage after primary transplantation and in all lineages after secondary transplantation. It is possible that deletion 
of cytoplasmic FH caused excessive protein succination and generalized cellular dysfunction. Isolated defect in mitochondrial FH however increased histone H3 methylation, possibly through inhibition of KDMs by fumarate[61・•]. Finally, deletion of the complex II component, $\mathrm{SdhD}$, also caused hematopoietic failure, although the cellular mechanism and precise effect on long-term HSCs were not determined[62].

\section{The role of mitochondrial dynamics}

Mitochondria form a network that undergoes continuous fusion and fission, a process called 'mitochondrial dynamics' and involved in regulation of apoptosis, metabolism and mtDNA maintenance[63••]. HSC have longer mitochondria than progenitors, a property conveyed by selective expression of the mitochondrial outer membrane fusion protein, Mfn2. Mfn2 is required for the maintenance of HSCs with extensive lymphoid potential. Mfn2 increased buffering of intracellular $\mathrm{Ca}^{2+}$, an effect mediated through its ER-mitochondria tethering activity[2,64], thereby negatively regulating nuclear translocation and transcriptional activity of Nuclear Factor of Activated T cells[65]. In addition to providing a mechanism underlying clonal heterogeneity among HSCs[66], this study formally identified a HSC maintenance mechanism mediated by mitochondria that does not directly depend on ATP production. Embryonic neural stem cells also possess elongated mitochondria. Here, inhibition of mitochondrial fusion inhibited self renewal and induced differentiation through enhanced ROS production and induction of a NFR2 transcriptional program[67••]. Mitochondrial dynamics can therefore likely affect cell fate choices through multiple mechanisms.

\section{Conclusions and perspectives}

The metabolic wiring of HSCs is insufficiently explained by residence in a hypoxic environment. There is room to consider the possibility that glycolysis serves a specific purpose critical for HSC maintenance, or that the apparent requirement for glycolytic ATP production is a compensation for hardwired low OxPhos in HSCs (Fig. 1). Intact mitochondrial function is nevertheless critical for HSC maintenance and the underlying mechanisms may include epigenetic changes. Because of the multiple roles of mitochondria and the distinct of effects of various mutations, it is difficult to determine the critical underlying mechanisms however. It is not known, for example, to what extent epigenetic changes cause the observed HSC defects. It is also interesting to note that HSCs are more resistant to starvation and radiation-induced apoptosis and show increased capacity of autophagy compared to progenitors[7,8]. As mitochondria play a critical role in cell death processes including apoptosis, necrosis and pyroptosis[3], as well as in the initiation of autophagy $[68,69]$, it is possible that the wiring of HSC mitochondria may contribute to the relative resistance of HSCs to demise in response to noxious stimuli.

Further insights into the specific roles of mitochondria in HSCs gained from more refined investigations may lead to strategies to achieve the still elusive, but clinically extremely important goal of maintaining functional HSCs in vitro. The rarity of HSCs is a major hurdle in this field, however. Hence, with the exception of a few studies[11,40•,42•], metabolic or epigenetic studies were performed on enriched progenitors, and not on purified HSCs. Application of novel metabolomics approaches adapted to small numbers of cells, while 
compromising on the breadth of metabolites detected and likely selecting for more abundant compounds, may offer an avenue forward[70••].

\section{Acknowledgments}

Supported by grants NIH R01CA167289 and NIH R01AG029626 (HWS). Flow cytometry was performed in the CCTI Flow Cytometry Core, supported in part by the Office of the Director, National Institutes of Health under awards S10RR027050 and S10OD020056.

\section{References}

1. Rossi L, Lin KK, Boles NC, Yang L, King KY, Jeong M, Mayle A, Goodell MA. Less is more: unveiling the functional core of hematopoietic stem cells through knockout mice. Cell Stem Cell. 2012; 11:302-317. [PubMed: 22958929]

2. Rizzuto R, De Stefani D, Raffaello A, Mammucari C. Mitochondria as sensors and regulators of calcium signalling. Nat Rev Mol Cell Biol. 2012; 13:566-578. [PubMed: 22850819]

3. Galluzzi L, Kepp O, Kroemer G. Mitochondrial regulation of cell death: a phylogenetically conserved control. Microb Cell. 2016; 3:101-108. [PubMed: 28357340]

4. West AP, Shadel GS, Ghosh S. Mitochondria in innate immune responses. Nat Rev Immunol. 2011; 11:389-402. [PubMed: 21597473]

5. Sena LA, Chandel NS. Physiological roles of mitochondrial reactive oxygen species. Mol Cell. 2012; 48:158-167. [PubMed: 23102266]

6. Reid MA, Dai Z, Locasale JW. The impact of cellular metabolism on chromatin dynamics and epigenetics. Nat Cell Biol. 2017; 19:1298-1306. [PubMed: 29058720]

7. Mohrin M, Bourke E, Alexander D, Warr MR, Barry-Holson K, Le Beau MM, Morrison CG, Passegue E. Hematopoietic stem cell quiescence promotes error-prone DNA repair and mutagenesis. Cell Stem Cell. 2010; 7:174-185. [PubMed: 20619762]

8. Warr MR, Binnewies M, Flach J, Reynaud D, Garg T, Malhotra R, Debnath J, Passegue E. FOXO3A directs a protective autophagy program in haematopoietic stem cells. Nature. 2013; 494:323-327. [PubMed: 23389440]

9. Simsek T, Kocabas F, Zheng J, Deberardinis RJ, Mahmoud AI, Olson EN, Schneider JW, Zhang CC, Sadek HA. The distinct metabolic profile of hematopoietic stem cells reflects their location in a hypoxic niche. Cell Stem Cell. 2010; 7:380-390. [PubMed: 20804973]

10. Suda T, Takubo K, Semenza GL. Metabolic regulation of hematopoietic stem cells in the hypoxic niche. Cell Stem Cell. 2011; 9:298-310. [PubMed: 21982230]

11. Takubo K, Nagamatsu G, Kobayashi CI, Nakamura-Ishizu A, Kobayashi H, Ikeda E, Goda N, Rahimi Y, Johnson RS, Soga T, et al. Regulation of glycolysis by Pdk functions as a metabolic checkpoint for cell cycle quiescence in hematopoietic stem cells. Cell Stem Cell. 2013; 12:49-61. [PubMed: 23290136]

12. Ryall JG, Dell'Orso S, Derfoul A, Juan A, Zare H, Feng X, Clermont D, Koulnis M, GutierrezCruz G, Fulco M, et al. The NAD(+)-dependent SIRT1 deacetylase translates a metabolic switch into regulatory epigenetics in skeletal muscle stem cells. Cell Stem Cell. 2015; 16:171-183. [PubMed: 25600643]

13. Manesia JK, Xu Z, Broekaert D, Boon R, van Vliet A, Eelen G, Vanwelden T, Stegen S, Van Gastel $\mathrm{N}$, Pascual-Montano A, et al. Highly proliferative primitive fetal liver hematopoietic stem cells are fueled by oxidative metabolic pathways. Stem Cell Res. 2015; 15:715-721. [PubMed: 26599326]

14. Ward PS, Thompson CB. Metabolic reprogramming: a cancer hallmark even warburg did not anticipate. Cancer Cell. 2012; 21:297-308. [PubMed: 22439925]

15. Ito K, Suda T. Metabolic requirements for the maintenance of self-renewing stem cells. Nat Rev Mol Cell Biol. 2014; 15:243-256. [PubMed: 24651542]

16. Cipolleschi MG, Dello Sbarba P, Olivotto M. The role of hypoxia in the maintenance of hematopoietic stem cells. Blood. 1993; 82:2031-2037. [PubMed: 8104535] 
17. Mantel CR, O'Leary HA, Chitteti BR, Huang X, Cooper S, Hangoc G, Brustovetsky N, Srour EF, Lee MR, Messina-Graham S, et al. Enhancing Hematopoietic Stem Cell Transplantation Efficacy by Mitigating Oxygen Shock. Cell. 2015; 161:1553-1565. [PubMed: 26073944]

18. Kubota Y, Takubo K, Suda T. Bone marrow long label-retaining cells reside in the sinusoidal hypoxic niche. Biochem Biophys Res Commun. 2008; 366:335-339. [PubMed: 18047833]

19. Takubo K, Goda N, Yamada W, Iriuchishima H, Ikeda E, Kubota Y, Shima H, Johnson RS, Hirao A, Suematsu M, et al. Regulation of the HIF-1alpha level is essential for hematopoietic stem cells. Cell Stem Cell. 2010; 7:391-402. [PubMed: 20804974]

20. Levesque JP, Winkler IG, Hendy J, Williams B, Helwani F, Barbier V, Nowlan B, Nilsson SK. Hematopoietic progenitor cell mobilization results in hypoxia with increased hypoxia-inducible transcription factor-1 alpha and vascular endothelial growth factor A in bone marrow. Stem Cells. 2007; 25:1954-1965. [PubMed: 17478585]

21. Wang YH, Israelsen WJ, Lee D, Yu VWC, Jeanson NT, Clish CB, Cantley LC, Vander Heiden MG, Scadden DT. Cell-state-specific metabolic dependency in hematopoiesis and leukemogenesis. Cell. 2014; 158:1309-1323. [PubMed: 25215489]

22. Parmar K, Mauch P, Vergilio JA, Sackstein R, Down JD. Distribution of hematopoietic stem cells in the bone marrow according to regional hypoxia. Proc Natl Acad Sci U S A. 2007; 104:54315436. [PubMed: 17374716]

23. Crane GM, Jeffery E, Morrison SJ. Adult haematopoietic stem cell niches. Nat Rev Immunol. 2017; 17:573-590. [PubMed: 28604734]

24. Spencer JA, Ferraro F, Roussakis E, Klein A, Wu J, Runnels JM, Zaher W, Mortensen LJ, Alt C, Turcotte R, et al. Direct measurement of local oxygen concentration in the bone marrow of live animals. Nature. 2014; 508:269-273. [PubMed: 24590072]

25. Nombela-Arrieta C, Pivarnik G, Winkel B, Canty KJ, Harley B, Mahoney JE, Park SY, Lu J, Protopopov A, Silberstein LE. Quantitative imaging of haematopoietic stem and progenitor cell localization and hypoxic status in the bone marrow microenvironment. Nat Cell Biol. 2013; 15:533-543. [PubMed: 23624405]

26. Ivan M, Kaelin WG Jr. The EGLN-HIF O2-Sensing System: Multiple Inputs and Feedbacks. Mol Cell. 2017; 66:772-779. [PubMed: 28622522]

27. Vukovic M, Sepulveda C, Subramani C, Guitart AV, Mohr J, Allen L, Panagopoulou TI, Paris J, Lawson H, Villacreces A, et al. Adult haematopoietic stem cells lacking Hif-1alpha self-renew normally. Blood. 2016

28. Guitart AV, Subramani C, Armesilla-Diaz A, Smith G, Sepulveda C, Gezer D, Vukovic M, Dunn $\mathrm{K}$, Pollard P, Holyoake TL, et al. Hif-2alpha is not essential for cell-autonomous hematopoietic stem cell maintenance. Blood. 2013; 122:1741-1745. [PubMed: 23894152]

29. Krock BL, Eisinger-Mathason TS, Giannoukos DN, Shay JE, Gohil M, Lee DS, Nakazawa MS, Sesen J, Skuli N, Simon MC. The aryl hydrocarbon receptor nuclear translocator is an essential regulator of murine hematopoietic stem cell viability. Blood. 2015; 125:3263-3272. [PubMed: 25855602]

30. Halvarsson C, Eliasson P, Jonsson JI. Pyruvate dehydrogenase kinase 1 is essential for transplantable mouse bone marrow hematopoietic stem cell and progenitor function. PLoS One. 2017; 12:e0171714. [PubMed: 28182733]

31. Kaelin WG Jr. ROS: really involved in oxygen sensing. Cell Metab. 2005; 1:357-358. [PubMed: 16054083]

32. Brunelle JK, Bell EL, Quesada NM, Vercauteren K, Tiranti V, Zeviani M, Scarpulla RC, Chandel NS. Oxygen sensing requires mitochondrial ROS but not oxidative phosphorylation. Cell Metab. 2005; 1:409-414. [PubMed: 16054090]

33. Guzy RD, Hoyos B, Robin E, Chen H, Liu L, Mansfield KD, Simon MC, Hammerling U, Schumacker PT. Mitochondrial complex III is required for hypoxia-induced ROS production and cellular oxygen sensing. Cell Metab. 2005; 1:401-408. [PubMed: 16054089]

34. Tan DQ, Suda T. Reactive Oxygen Species and Mitochondrial Homeostasis as Regulators of Stem Cell Fate and Function. Antioxid Redox Signal. 2017 
35. Xiao N, Jani K, Morgan K, Okabe R, Cullen DE, Jesneck JL, Raffel GD. Hematopoietic stem cells lacking Ott1 display aspects associated with aging and are unable to maintain quiescence during proliferative stress. Blood. 2012; 119:4898-4907. [PubMed: 22490678]

36. Vannini N, Girotra M, Naveiras O, Nikitin G, Campos V, Giger S, Roch A, Auwerx J, Lutolf MP. Specification of haematopoietic stem cell fate via modulation of mitochondrial activity. Nat Commun. 2016; 7:13125. [PubMed: 27731316]

37. Mohrin M, Shin J, Liu Y, Brown K, Luo H, Xi Y, Haynes CM, Chen D. Stem cell aging. A mitochondrial UPR-mediated metabolic checkpoint regulates hematopoietic stem cell aging. Science. 2015; 347:1374-1377. [PubMed: 25792330]

38. Romero-Moya D, Bueno C, Montes R, Navarro-Montero O, Iborra FJ, Lopez LC, Martin M, Menendez P. Cord blood-derived CD34+ hematopoietic cells with low mitochondrial mass are enriched in hematopoietic repopulating stem cell function. Haematologica. 2013; 98:1022-1029. [PubMed: 23349299]

39. Ito K, Turcotte R, Cui J, Zimmerman SE, Pinho S, Mizoguchi T, Arai F, Runnels JM, Alt C, Teruya-Feldstein J, et al. Self-renewal of a purified Tie2+ hematopoietic stem cell population relies on mitochondrial clearance. Science. 2016; 354:1156-1160. [PubMed: 27738012]

40. Ho TT, Warr MR, Adelman ER, Lansinger OM, Flach J, Verovskaya EV, Figueroa ME, Passegue E. Autophagy maintains the metabolism and function of young and old stem cells. Nature. 2017; 543:205-210. [PubMed: 28241143]

41. Sandoval H, Thiagarajan P, Dasgupta SK, Schumacher A, Prchal JT, Chen M, Wang J. Essential role for Nix in autophagic maturation of erythroid cells. Nature. 2008; 454:232-235. [PubMed: 18454133]

42. de Almeida MJ, Luchsinger LL, Corrigan DJ, Williams LJ, Snoeck HW. Dye-Independent Methods Reveal Elevated Mitochondrial Mass in Hematopoietic Stem Cells. Cell Stem Cell. 2017; 21:725-729. e724. [PubMed: 29198942]

43. Mantel C, Messina-Graham S, Moh A, Cooper S, Hangoc G, Fu XY, Broxmeyer HE. Mouse hematopoietic cell-targeted STAT3 deletion: stem/progenitor cell defects, mitochondrial dysfunction, ROS overproduction, and a rapid aging-like phenotype. Blood. 2012; 120:2589-2599. [PubMed: 22665934]

44. Zhou S, Schuetz JD, Bunting KD, Colapietro AM, Sampath J, Morris JJ, Lagutina I, Grosveld GC, Osawa M, Nakauchi $\mathrm{H}$, et al. The ABC transporter Bcrp1/ABCG2 is expressed in a wide variety of stem cells and is a molecular determinant of the side-population phenotype. Nat Med. 2001; 7:1028-1034. [PubMed: 11533706]

45. Schinkel AH, Mayer U, Wagenaar E, Mol CA, van Deemter L, Smit JJ, van der Valk MA, Voordouw AC, Spits H, van Tellingen O, et al. Normal viability and altered pharmacokinetics in mice lacking mdr1-type (drug-transporting) P-glycoproteins. Proc Natl Acad Sci U S A. 1997; 94:4028-4033. [PubMed: 9108099]

46. Chen C, Liu Y, Liu R, Ikenoue T, Guan KL, Liu Y, Zheng P. TSC-mTOR maintains quiescence and function of hematopoietic stem cells by repressing mitochondrial biogenesis and reactive oxygen species. J Exp Med. 2008; 205:2397-2408. [PubMed: 18809716]

47. Maryanovich M, Zaltsman Y, Ruggiero A, Goldman A, Shachnai L, Zaidman SL, Porat Z, Golan K, Lapidot T, Gross A. An MTCH2 pathway repressing mitochondria metabolism regulates haematopoietic stem cell fate. Nat Commun. 2015; 6:7901. [PubMed: 26219591]

48. Norddahl GL, Pronk CJ, Wahlestedt M, Sten G, Nygren JM, Ugale A, Sigvardsson M, Bryder D. Accumulating mitochondrial DNA mutations drive premature hematopoietic aging phenotypes distinct from physiological stem cell aging. Cell Stem Cell. 2011; 8:499-510. [PubMed: 21549326]

49. Yu WM, Liu X, Shen J, Jovanovic O, Pohl EE, Gerson SL, Finkel T, Broxmeyer HE, Qu CK. Metabolic regulation by the mitochondrial phosphatase PTPMT1 is required for hematopoietic stem cell differentiation. Cell Stem Cell. 2013; 12:62-74. [PubMed: 23290137]

50. Inoue S, Noda S, Kashima K, Nakada K, Hayashi J, Miyoshi H. Mitochondrial respiration defects modulate differentiation but not proliferation of hematopoietic stem and progenitor cells. FEBS Lett. 2010; 584:3402-3409. [PubMed: 20600007] 
51. Gan B, Hu J, Jiang S, Liu Y, Sahin E, Zhuang L, Fletcher-Sananikone E, Colla S, Wang YA, Chin $\mathrm{L}$, et al. Lkb1 regulates quiescence and metabolic homeostasis of haematopoietic stem cells. Nature. 2010; 468:701-704. [PubMed: 21124456]

52. Gurumurthy S, Xie SZ, Alagesan B, Kim J, Yusuf RZ, Saez B, Tzatsos A, Ozsolak F, Milos P, Ferrari F, et al. The Lkb1 metabolic sensor maintains haematopoietic stem cell survival. Nature. 2010; 468:659-663. [PubMed: 21124451]

53. Nakada D, Saunders TL, Morrison SJ. Lkb1 regulates cell cycle and energy metabolism in haematopoietic stem cells. Nature. 2010; 468:653-658. [PubMed: 21124450]

54. Sahin E, Depinho RA. Linking functional decline of telomeres, mitochondria and stem cells during ageing. Nature. 2010; 464:520-528. [PubMed: 20336134]

55. Rimmele P, Liang R, Bigarella CL, Kocabas F, Xie J, Serasinghe MN, Chipuk J, Sadek H, Zhang $\mathrm{CC}$, Ghaffari S. Mitochondrial metabolism in hematopoietic stem cells requires functional FOXO3. EMBO Rep. 2015; 16:1164-1176. [PubMed: 26209246]

56. Ducker GS, Rabinowitz JD. One-Carbon Metabolism in Health and Disease. Cell Metab. 2017; 25:27-42. [PubMed: 27641100]

57. Wellen KE, Hatzivassiliou G, Sachdeva UM, Bui TV, Cross JR, Thompson CB. ATP-citrate lyase links cellular metabolism to histone acetylation. Science. 2009; 324:1076-1080. [PubMed: 19461003]

58- Martinez-Reyes I, Diebold LP, Kong H, Schieber M, Huang H, Hensley CT, Mehta MM, Wang T, Santos JH, Woychik R, et al. TCA Cycle and Mitochondrial Membrane Potential Are Necessary for Diverse Biological Functions. Mol Cell. 2016; 61:199-209. The TCA can maintain epigenetic marks, even in the presence of impaired mitochondrial respiration, thus directly linking TCA activity to epigenetic modifications. [PubMed: 26725009]

59••. Anso E, Weinberg SE, Diebold LP, Thompson BJ, Malinge S, Schumacker PT, Liu X, Zhang Y, Shao Z, Steadman M, et al. The mitochondrial respiratory chain is essential for haematopoietic stem cell function. Nat Cell Biol. 2017; 19:614-625. Deletion of complex III function directly impairs HSC maintenance, possible through genome-wide epigenetic changes. [PubMed: 28504706]

60•. Liu X, Zhang Y, Ni M, Cao H, Signer RAJ, Li D, Li M, Gu Z, Hu Z, Dickerson KE, et al. Regulation of mitochondrial biogenesis in erythropoiesis by mTORC1-mediated protein translation. Nat Cell Biol. 2017; 19:626-638. Impaired mitochondrial function in the erythroid lineage severely compromises erythropoiesis, possibly through epigenetic changes that are however, distinct from those induced by Risp-deletion in ref. 59. [PubMed: 28504707]

61••. Guitart AV, Panagopoulou TI, Villacreces A, Vukovic M, Sepulveda C, Allen L, Carter RN, van de Lagemaat LN, Morgan M, Giles P, et al. Fumarate hydratase is a critical metabolic regulator of hematopoietic stem cell functions. J Exp Med. 2017; 214:719-735. A block in the TCA induced by mitochondrial fumarate hydratase deletion affects HSC maintenance, possibly through induction of epigenetic changes. [PubMed: 28202494]

62. Bejarano-Garcia JA, Millan-Ucles A, Rosado IV, Sanchez-Abarca LI, Caballero-Velazquez T, Duran-Galvan MJ, Perez-Simon JA, Piruat JI. Sensitivity of hematopoietic stem cells to mitochondrial dysfunction by SdhD gene deletion. Cell Death Dis. 2016; 7:e2516. [PubMed: 27929539]

63. Chen H, Chan DC. Mitochondrial Dynamics in Regulating the Unique Phenotypes of Cancer and Stem Cells. Cell Metab. 2017; 26:39-48. [PubMed: 28648983]

64. de Brito OM, Scorrano L. Mitofusin 2 tethers endoplasmic reticulum to mitochondria. Nature. 2008; 456:605-610. [PubMed: 19052620]

65. Luchsinger LL, de Almeida MJ, Corrigan DJ, Mumau M, Snoeck HW. Mitofusin 2 maintains haematopoietic stem cells with extensive lymphoid potential. Nature. 2016; 529:528-531. Identification maintenance mechanism specifically for lymphoid-biased HSC mediated by mitochondria that does not directly depend on ATP production, but involved mitochondrial calcium buffering. [PubMed: 26789249]

66. Muller-Sieburg CE, Sieburg HB. Clonal diversity of the stem cell compartment. Curr Opin Hematol. 2006; 13:243-248. [PubMed: 16755220] 
67••. Khacho M, Clark A, Svoboda DS, Azzi J, MacLaurin JG, Meghaizel C, Sesaki H, Lagace DC, Germain M, Harper ME, et al. Mitochondrial Dynamics Impacts Stem Cell Identity and Fate Decisions by Regulating a Nuclear Transcriptional Program. Cell Stem Cell. 2016 Mitochondrial dynamics directly affect stem cell fate choice through retrograde signaling to the nucleus.

68. Hamasaki M, Furuta N, Matsuda A, Nezu A, Yamamoto A, Fujita N, Oomori H, Noda T, Haraguchi T, Hiraoka Y, et al. Autophagosomes form at ER-mitochondria contact sites. Nature. 2013; 495:389-393. [PubMed: 23455425]

69. Hailey DW, Rambold AS, Satpute-Krishnan P, Mitra K, Sougrat R, Kim PK, Lippincott-Schwartz J. Mitochondria supply membranes for autophagosome biogenesis during starvation. Cell. 2010; 141:656-667. [PubMed: 20478256]

70••. Agathocleous M, Meacham CE, Burgess RJ, Piskounova E, Zhao Z, Crane GM, Cowin BL, Bruner E, Murphy MM, Chen W, et al. Ascorbate regulates haematopoietic stem cell function and leukaemogenesis. Nature. 2017; 549:476-481. Development of metabolomics in small numbers of cells, which revealed a critical role for ascorbate in HSC function and leukemogenesis through regulation of TET function. [PubMed: 28825709] 


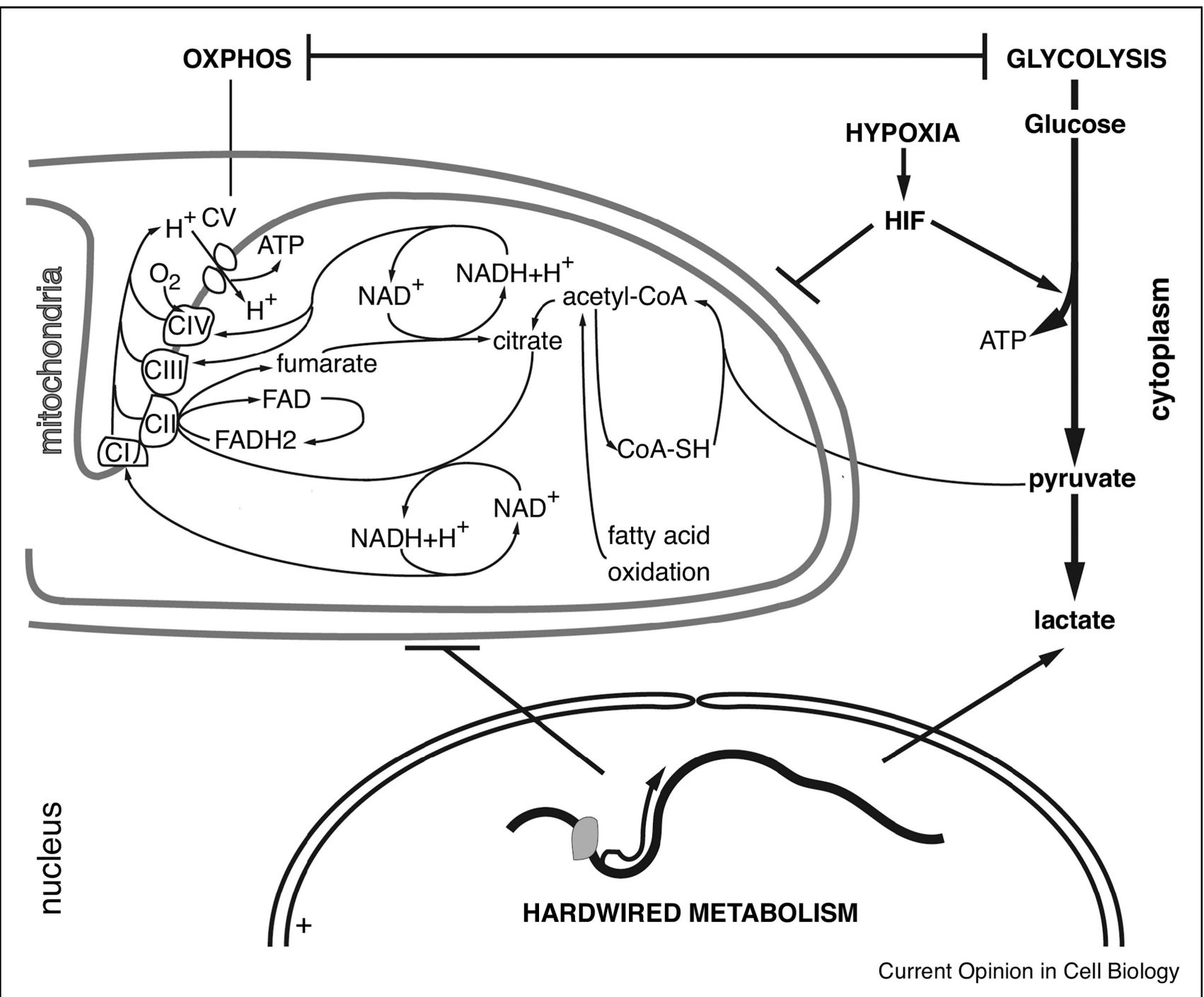

Figure 1. HSC metabolism

Schematic representation of HSC metabolism. Three hypotheses to explain the preponderance of glycolytic ATP production are depicted: a HIF-mediated response to hypoxia, transcriptionally hardwired glycolysis, or a compensatory response to a hardwired attenuation of mitochondrial respiration. 


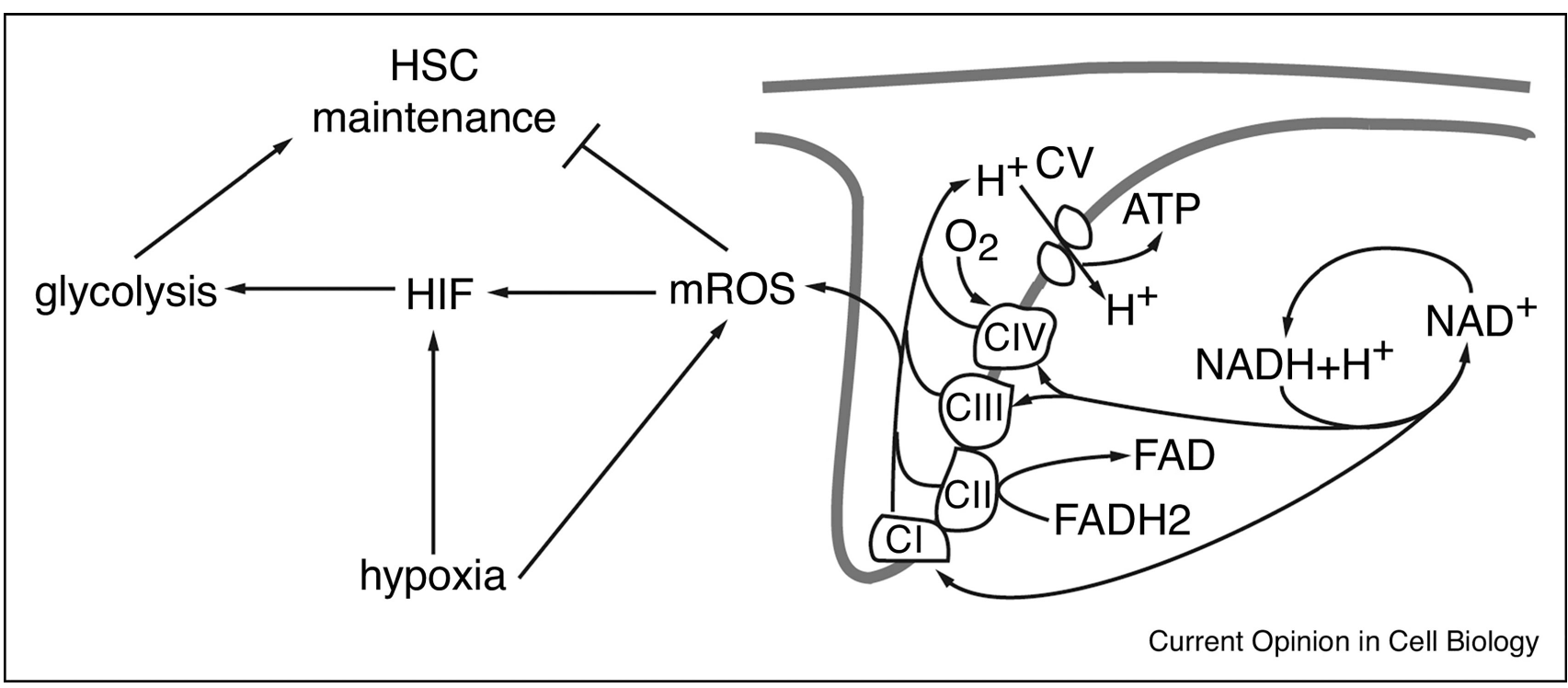

Figure 2. The mROS conundrum

Schematic representation of the presumed roles of mROS in HSC function and in hypoxia signaling. mROS directly negatively affect HSC function, but may on the other hand stabilize HIF and activate glycolysis, which is required for maintaining HSC function. 


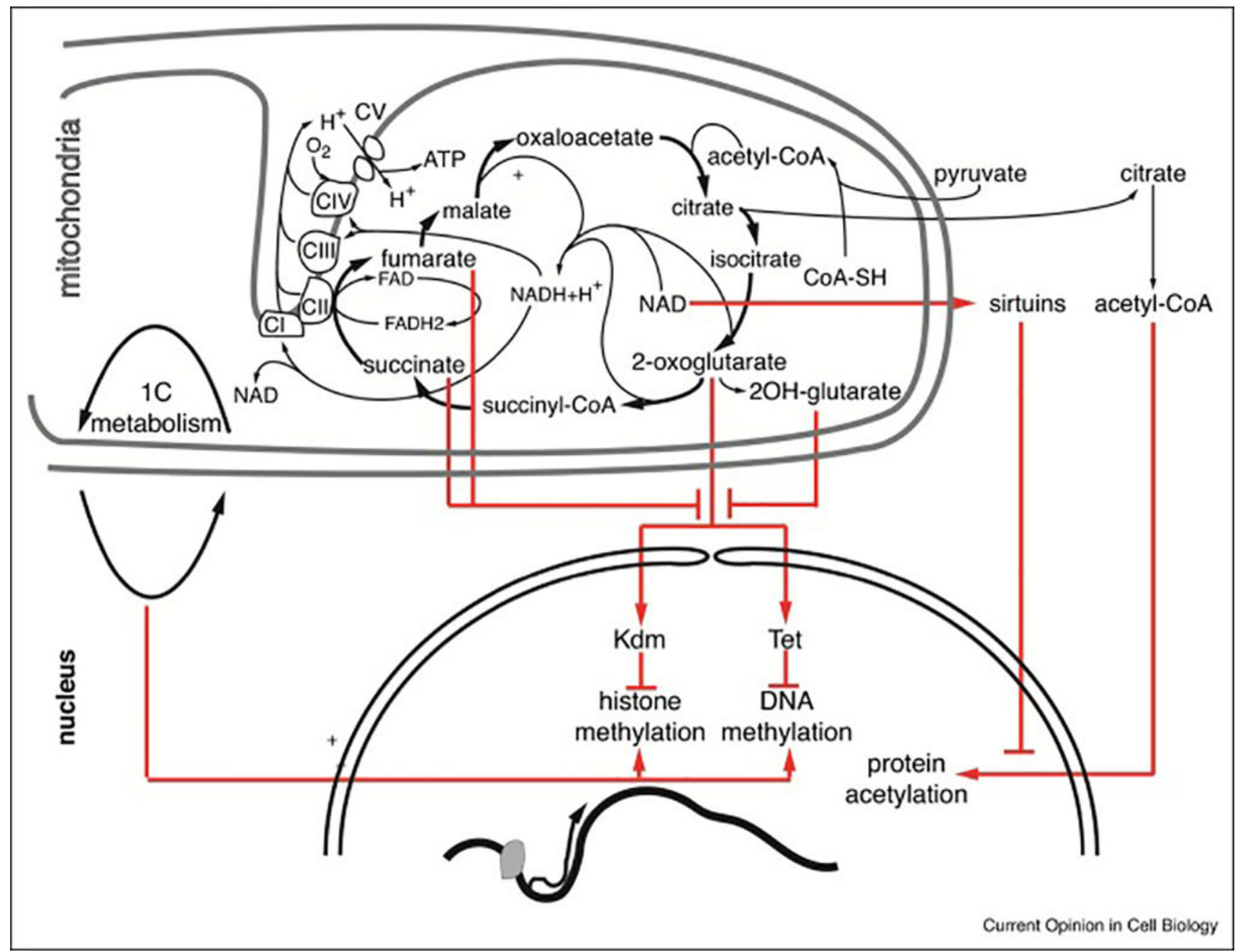

Figure 3. Mitochondrial metabolism and epigenetics

Schematic representation of mitochondrial metabolites that are used as epigenetic marks or inhibit epigenetic modifications. 


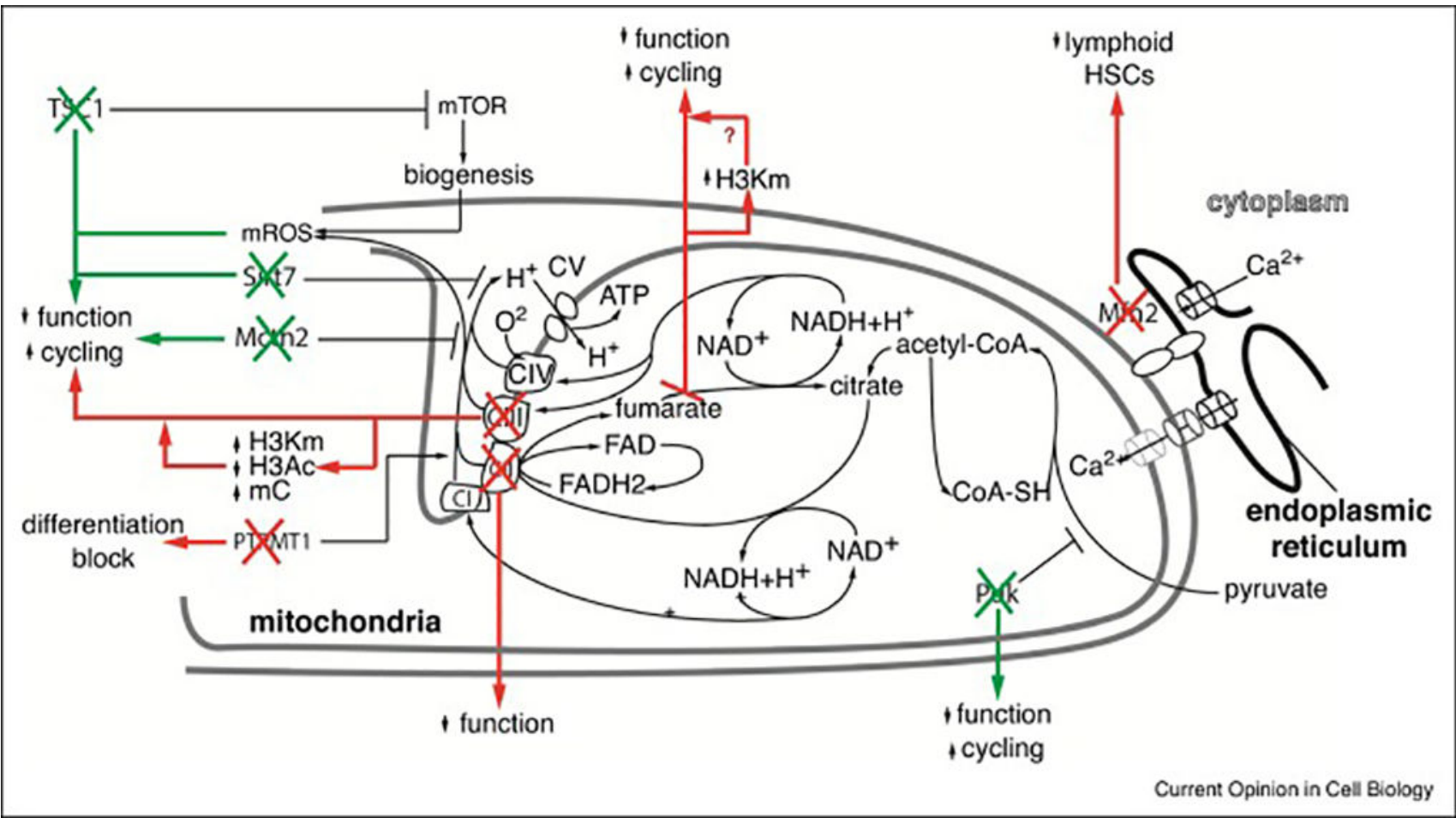

Figure 4. Mitochondrial function and HSC maintenance

Schematic representation of recently described mutants where impaired or enhanced mitochondrial function is detrimental to HSC maintenance. Green arrows represent mutants with enhanced mitochondrial function, red arrows represent mutants with impaired mitochondrial function. 